\title{
Case-by-Case Surveillance for Bacterial Meningitis in Benin: Data Analysis, 2016 to 2018
}

\section{Togbemabou Primous Godjedo1,2, Moussiliou Noël Paraiso3, Alidehou Jerrold Agbankpe4, Tamegnon Victorien Dougnon4, Cyriaque Degbey ${ }^{3}$, Angele Ahoyo4, Lamine Baba-Moussa5, Honoré Bankole ${ }^{2,4}$}

\author{
${ }^{1}$ Epidemiological Surveillance Service, Ministry of Public Health, Cotonou, Benin \\ ${ }^{2}$ National Health Laboratory, Ministry of Public Health, Cotonou, Benin \\ ${ }^{3}$ Regional Institute of Public Health, University of Abomey-Calavi, Cotonou, Benin \\ ${ }^{4}$ Research Unit in Applied Microbiology and Pharmacology of Natural Substances, Research Laboratory in Applied Biology, \\ Polytechnic School of Abomey-Calavi, University of Abomey-Calavi, Cotonou, Benin \\ ${ }^{5}$ Laboratory of Biology and Molecular Typing in Microbiology, Faculty of Science and Technology, University of Abomey-Calavi, \\ UAC, Cotonou, Benin \\ Email: agbankpejerrold@yahoo.fr
}

How to cite this paper: Godjedo, T.P., Paraiso, M.N., Agbankpe, A.J., Dougnon, T.V., Degbey, C., Ahoyo, A., Baba-Moussa, L. and Bankole, H. (2020) Case-By-Case Surveillance for Bacterial Meningitis in Benin: Data Analysis, 2016 to 2018. Open Journal of Epidemiology, 10, 1-14. https://doi.org/10.4236/ojepi.2020.101001

Received: November 3, 2019

Accepted: December 6, 2019

Published: December 9, 2019

Copyright $\odot 2020$ by author(s) and Scientific Research Publishing Inc. This work is licensed under the Creative Commons Attribution International License (CC BY 4.0).

http://creativecommons.org/licenses/by/4.0/

c) (i) Open Access

\begin{abstract}
Background: Bacterial meningitis is an inflammation of the meninges caused mainly by three bacterial species Neisseria meningitidis, Streptococcus pneumoniae and Haemophilus influenzae that are transmitted by nasopharyngeal secretions emitted by carriers. Meningitis is a public health problem in Benin, like all countries in the African meningitis belt. This study aims to analyze the epidemiological surveillance data of meningitis in Benin from 2016 to 2018. Methods: Each suspect case of meningitis was recorded and Cerebrospinal Fluid (CSF) samples were collected. CSF collection was accompanied by the Integrated Disease Surveillance and Response form. This sheet provides information on the patient's social-demographic and epidemiological data. CSF specimens were sent to the laboratory for analysis and identification (Gram stain, biochemical parameters, and latex agglutination test) of pathogens according to the WHO standards. Results: Of the 2992 patients with suspected meningitis, 2893 were hospitalized with a death rate of $9.4 \%(281 / 2992)$. The sex ratio of registered patients was 1.29 in favor of men. The median age was 4 years (min: 0; max: 90). Patients younger than five years were the most represented (44.8\%). During the study period, there was a decrease in the incidence of meningitis per 100,000 inhabitants (6.3 to 3.2 from 2016 to 2018). Of 2928 CSF samples collected we were able to identify 899 pathogenic bacterial species. The most represented species are
\end{abstract}


S. pneumoniae (63.4\%), $N$. meningitidis (24.4\%) and $H$. influenzae (12.2\%). Conclusion: The burden of disease is disproportionate in the northern departments as in others. The frequency of bacterial meningitis in the northern region increased during the study period. However, deaths have been recorded in the departments of the South ("Atlantic", "Plateau"). This suggests an improvement in epidemiological surveillance and case management throughout the national territory.

\section{Keywords}

Benin, Meningitidis, Epidemiologic Surveillance, CSF, Bacterial Meningitidis

\section{Introduction}

Generally caused by infectious agents such as bacteria, fungi, viruses, parasites and rickettsia, meningitis is an acute inflammation of the brain's meninges. The disease is called cerebrospinal meningitis (CSM) if the meninges of the brain and spinal cord are involved [1]. It is an epidemic-prone disease that affects a significant proportion of the world's population if it is caused by a Neisseria meningitidis. The case fatality rate can reach $50 \%$ in the absence of treatment [2]. The most common form of meningitis is bacterial meningitis [3]. Meningococcal meningitis is caused specifically by the type species called Neisseria meningitidis. Haemophilus influenzae (type b, Hib), Streptococcus pneumoniae, Neisseria meningitidis, and group B streptococci is common agents of bacterial meningitis [4]. Meningitis is characterized by symptoms ranging from fever, headache, stiff neck, photophobia, and muscle aches to vomiting and diarrhea [2]. The epidemics of meningitis affect about 14 countries in sub-Saharan Africa including Benin, grouped together in the "African meningitis belt" [5]. The disease is a threat to public health in Africa. During the period 1993-2012, nearly one million suspected cases were reported, including 100,000 estimated deaths [6]. The bacterial form, caused by the meningococcal Neisseria meningitidis type A, predominates in Africa with $80 \%$ to $85 \%$ of cases, especially between 1 and 30 years [7]. Infections are particularly serious and can be fatal in the absence of adequate antibiotic treatment. The mortality rate varies from $16 \%$ to $37 \%$ in adults and the neurological sequelae occur in $30 \%$ to $52 \%$ of survivors. Children with meningitis attacks die in $2 \%$ to $15 \%$ of cases and $10 \%$ to $15 \%$ of survivors have various sequelae [8]. As a result, prompt treatment is recommended, especially in children [9].

In Benin, the incidence of meningitis in the "Atacora" and "Donga" departments was 71 to 619 per 100,000 inhabitants in 2004 with a case fatality rate (CFR) of 3.1\% [10]. In 2003, Benin and other African countries were supported by the World Health Organization and the Meningitis Vaccine Project, a joint WHO/PATH initiative in the establishment of a strengthened surveillance network for meningitis [3]. The surveillance system is well organized with standard 
operating procedures to improve the recording and management of data on suspected cases notified each epidemiological week or daily during outbreaks by peripheral health centers and hospitals, to those Responsible for Epidemiological Surveillance Centers (RESC) of the health zones that transmit them by telephone or e-mail to the authorities (national level) through the Departmental Service of Public Health [11]. The collected cerebrospinal fluid (CSF) specimens accompanied by a notice card containing the patient's personal information and the corresponding clinical information are sent by the hospitals' laboratories after manipulation to the bacteriology section of the Ministry's National Public Health Laboratory of Health for confirmation. Despite this structured system, Benin does not have complete epidemiological information on meningitis. It is to remedy this situation, that in collaboration with the Department of Epidemiology and Health Surveillance of the borders, port and airport (DEHS) of the National Direction of Public Health (NDPH), Ministry of Health that we initiated this study. It aims to know epidemiological profile of meningitis in Benin during the period from 2016 to 2018 and to identify the population at risk in the framework of the planning of the best activities of preparation and response to a possible epidemic outbreak.

\section{Material and Methods}

\subsection{Study Area}

This study was conducted in Republic of Benin. It is a coastal country of West Africa, with an area of $114,763 \mathrm{~km}^{2}$. Annual average temperatures range from 26 to $28^{\circ} \mathrm{C}$ in the country. The climate is subequatorial in the south, humid tropical transition in the center and tropical dry in the north [12]. The population was estimated at 9,983,884 inhabitants in 2013 [13], including 51.2\% of females. About half of the population is over 15 years old. The health system has a pyramidal structure, modeled on the administrative division. It has 3 levels: central, intermediate and peripheral [14]. The peripheral level is represented by the health zone whose head is the Medical Coordinator of the Health Zone while the intermediate level is represented by the department with as head, the Departmental Director of Health. At the central level, it is represented by the Ministry of Health, which is the level of design and decision-making in health sector development policy.

\subsection{Methodology}

We conducted a prospective, descriptive, targeted surveillance study that relied on data collected from suspected meningitis cases notified to epidemiological surveillance centers across Benin between January 1, 2016 and December 31, 2018.

\subsection{Data Collection}

Included in the study were all patients with a high sudden-onset fever (rectal 
temperature $>38.5^{\circ} \mathrm{C}$ or axillary $>38.0^{\circ} \mathrm{C}$ ) and one of the following signs: stiff neck, impaired consciousness or other meningeal signs throughout the national territory and from which a sample of Cerebrospinal Fluid was collected.

After identifying a suspected case of meningitis, the collection of Cerebrospinal Fluid (CSF) was sent to the hospital laboratory for analysis; and is accompanied by the completed Integrated Disease Surveillance and Response form. On this form, the social (age, sex and area of origin) and clinical (patient hospitalized or not, the type of case, appearance of CSF samples, vaccinated or non-vaccinated patient) information of the patient was recorded.

In the case where the zone hospital did not have a bacteriology section in its laboratory, the samples were put on Trans-Isolat transport medium and sent to the departmental laboratories having a bacteriology session within 48 hours at most. All samples are then sent to the National Public Health Laboratory (LNSP) for bacteriological analysis for confirmation and identification of bacterial species.

\subsection{Bacteriological Analysis of CSF Samples}

Macroscopic examination of CSF samples was performed and samples were classified into four categories: clear, turbid, xanthochrome and hemorrhagic. Gram stain was performed on samples for looking for Gram-negative Cocci, Gram-positive Cocci, and Gram-negative Bacilli for the respective presumptive identification of Neisseria meningitidis, Streptococcus pneumoniae, and Haemophilus influenzae. Bacteriological culture was carried out for isolation of strains of Neisseria meningitidis, Streptococcus pneumoniae and Haemophilus influenzae. CSF samples were streaked onto Columbia blood agar plates and chocolate agar to isolate the pure colonies. After inoculation, the agar plates were incubated at $37^{\circ} \mathrm{C}$ anaerobically for 24 - 48 hours.

We proceeded to the observation of colonies appeared, the search for catalase, cytochrome oxidase and gram controlfor identification of bacteria. All cocci and gram-negative catalase and cytochrome oxidase (Neisseria meningitidis, Haemophilus influenzae) positive strains as well as catalase and cytochrome oxidase (Streptococcus pneumoniae) gram-positive cocci strains were selected. The identity of the isolates was confirmed by latex agglutination, as well as serogrouping of Neisseria meningitidis species. The latex agglutination was carried out using a Pastorex meningitis kit (Bio-Rad) to detect $H$. influenzae, $S$. pneumoniae and $N$. meningitidis antigens of groups $\mathrm{A}, \mathrm{B}, \mathrm{C}, \mathrm{Y}$ and $\mathrm{W}$, and a Directigen meningitis kit (Becton Dickinson) to detect $N$. meningitidis antigens of groups $\mathrm{X}$ and $\mathrm{Z}$. The kits were used according to the manufacturer's instructions.

\subsection{Statistical Analysis}

The epidemiological data of the patients were recorded in an Excel spreadsheet and analyzed with the SAS software. Quantitative variables were presented as 
mean \pm standard deviation with the max/min range. Qualitative variables were presented as numbers and percentages. The graphs were made with Graphpad Prism 7 software.

\subsection{Ethical Considerations}

In Benin, ethical approval was not required for routine surveillance of meningitis, as it had been approved as part of the systematic diagnosis algorithm in the Ministry of Health. However, informed consent was sought from parents or guardians of surveillance participants.

\section{Results}

\subsection{Demographic and Clinical Characteristics}

We identified 2992 individuals suspected of meningitis, of whom 2893 admitted (96.7\%) to the hospital from 2016 to 2018 . The sex ratio of the individuals included in our study is 1.29 in favor of men, with a median age of 4 years (min: 0; max: 90). Individuals under five represent the most represented age group $44.8 \%$ (1339 individuals). The least represented age group is 55 to 59 years old $(0.8 \%)$. More than half of the individuals (77.1\%) included in this study came from a rural area with 281 deaths (9.4\%) identified throughout the three years of study. Of the 2992 suspected meningitis cases included in this study, CSF samples were collected from 2928 patients, for a sample rate of $97.9 \%$. CSF samples were taken from $98.4 \%$ hospitalized patients. One thousand six hundred and thirty-nine (56\%) CSF samples were collected from men and 1285 (43.9) from women. 273 (9.3\%) patients died with disease, but 2529 (86.4\%) survived (Table $1)$.

Table 1. Characteristics of patients with suspected bacterial meningitis in the Republic of Benin, 2016-2018.

\begin{tabular}{cccc}
\hline Characteristics & \multicolumn{3}{c}{ Number of suspect Number of collected Number of CSF sample } \\
cases (\%) & CSF samples (\%) & not collected (\%) & p-value \\
\hline Age group & & & \\
{$[0-5[$} & $1339(44.8)$ & $1326(45.3)$ & $13(20.3)$ \\
{$[5-10[$} & $397(13.3)$ & $392(13.4)$ & $05(7.8)$ \\
{$[10-15[$} & $235(7.9)$ & $231(7.9)$ & $04(6.2)$ \\
{$[15-20[$} & $111(3.7)$ & $107(3.7)$ & $04(6.2)$ \\
{$[20-25[$} & $70(2.3)$ & $69(2.4)$ & $01(1.6)$ \\
{$[25-30[$} & $54(1.8)$ & $54(1.8)$ & 00 \\
{$[30-35[$} & $54(1.8)$ & $53(1.8)$ & $01(1.6)$ \\
{$[35-40[$} & $67(2.2)$ & $65(2.2)$ & $02(3.1)$ \\
{$[40-45[$} & $45(1.5)$ & $45(1.5)$ & 00 \\
{$[45-50[$} & $36(1.2)$ & $36(1.2)$ & 00 \\
{$[50-55[$} & $43(1.4)$ & $42(1.4)$ & $01(1.6)$ \\
\hline
\end{tabular}




\section{Continued}

\begin{tabular}{|c|c|c|c|c|}
\hline$[55-60[$ & $24(0.8)$ & $24(0.8)$ & 00 & \\
\hline $60+$ & $72(2.4)$ & $71(2.4)$ & $01(1.6)$ & \\
\hline Unknown & 445 (14.9) & $413(14.1)$ & $32(50.0)$ & \\
\hline Sex & & & & - \\
\hline Male & $1661(55.5)$ & $1639(56.0)$ & $22(34.4)$ & \\
\hline Female & $1292(43.2)$ & $1285(43.9)$ & $07(10.9)$ & \\
\hline Unknown & $39(1.3)$ & $04(0.1)$ & $35(54.7)$ & \\
\hline Area of residence & & & & - \\
\hline Urban & $554(18.5)$ & $546(18.6)$ & $08(12.5)$ & \\
\hline Rural & $2307(77.1)$ & $2290(78.2)$ & $17(26.6)$ & \\
\hline Unknown & $131(4.4)$ & $92(3.1)$ & $39(60.9)$ & \\
\hline \multicolumn{5}{|c|}{ Place of consultation } \\
\hline Hospital & $2893(96.7)$ & $2880(98.4)$ & $13(20.3)$ & 0.03 \\
\hline External & $57(1.9)$ & $42(1.4)$ & $15(23.4)$ & \\
\hline Unknown & $42(1.4)$ & $06(0.2)$ & $36(56.3)$ & \\
\hline Outcome & & & & - \\
\hline Death & $281(9.4)$ & $273(9.3)$ & $08(12.5)$ & \\
\hline Living & $2571(85.9)$ & $2529(86.4)$ & $42(65.6)$ & \\
\hline Unknown & $140(4.7)$ & $126(4.3)$ & $14(21.9)$ & \\
\hline Total & $2992(100)$ & $2928(100)$ & $64(100)$ & \\
\hline
\end{tabular}

Source: DEHS/NDPH $(2016,2017$, and 2018).

The annual distribution of suspected meningitis cases with incidences per 100,000 population and annual lethality rates are shown in Table 2. In 2017, we recorded more suspect cases (1148) than in 2016 and 2018. In 2016, the number of suspect cases was 1060 and 748 in 2018. However, the highest lethality (13.4\%) was observed in 2016, with an incidence of 6.3 per 100,000 inhabitants. In 2017, the incidence was 6.8 with a case fatality rate of $7.1 \%$. The lowest incidence (3.2) was observed in 2018 with a lethality of 7.6\% (Table 2).

Of the 12 departments in Benin, 10 were included in our study. Department of "Atacora" was the department with the highest number 2095 of suspected cases of meningitis, followed by Borgou with 392 suspected cases and Alibori with 286 . With lethality rates ranging from $8.4 \%$ to $10.5 \%$. "Atlantique" and "Plateau" departments with low numbers of suspect cases (Figure 1), respectively, have the highest CFR (12.5\%). The age group under 5 years has recorded more deaths (130) with a lethality of $9.7 \%$, survival of the group of 5 to 9 years with 37 cases of death recorded and a CFR of $9.3 \%$.

There is no significant difference $(p>0.05)$ between suspected cases and deaths among male and female. But there was a higher CFR (9.8\%) among male than female (Figure 2). Distribution of suspect cases and deaths by months of 
Table 2. Estimated annual incidence and case-fatality rate (CFR) of meningitis bacteria in Benin, 2016-2018.

\begin{tabular}{cccccc}
\hline Years & Population $^{\text {a }}$ & $\begin{array}{c}\text { Numberof } \\
\text { suspect cases }\end{array}$ & $\begin{array}{c}\text { Number of } \\
\text { death }\end{array}$ & $\begin{array}{c}\text { Incidence/100,000 } \\
\text { inhabitants }\end{array}$ & CFR (\%) \\
\hline 2016 & 11.027 .717 & 1060 & 142 & 6.3 & 13.4 \\
2017 & 11.485 .270 & 1148 & 82 & 6.8 & 7.1 \\
2018 & 11.496 .140 & 748 & 57 & 3.2 & 7.6 \\
\hline
\end{tabular}

a: National Institute of Statistics and Economic Analysis [13].

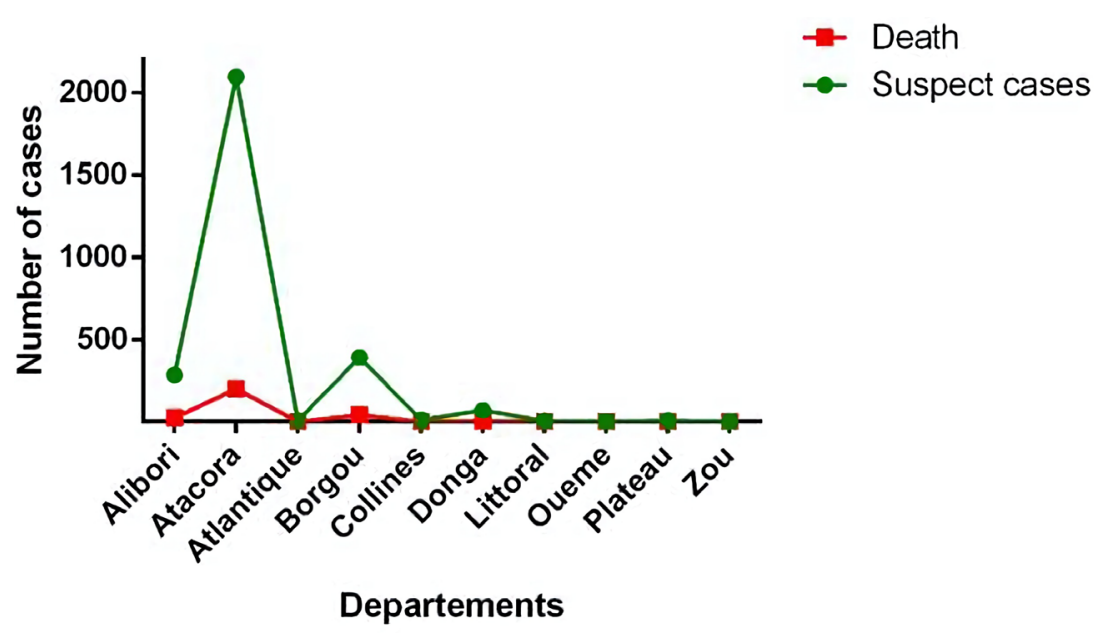

Figure 1. Distribution by department of suspected cases and deaths due to bacterial meningitis in the Republic of Benin, 2016-2018.

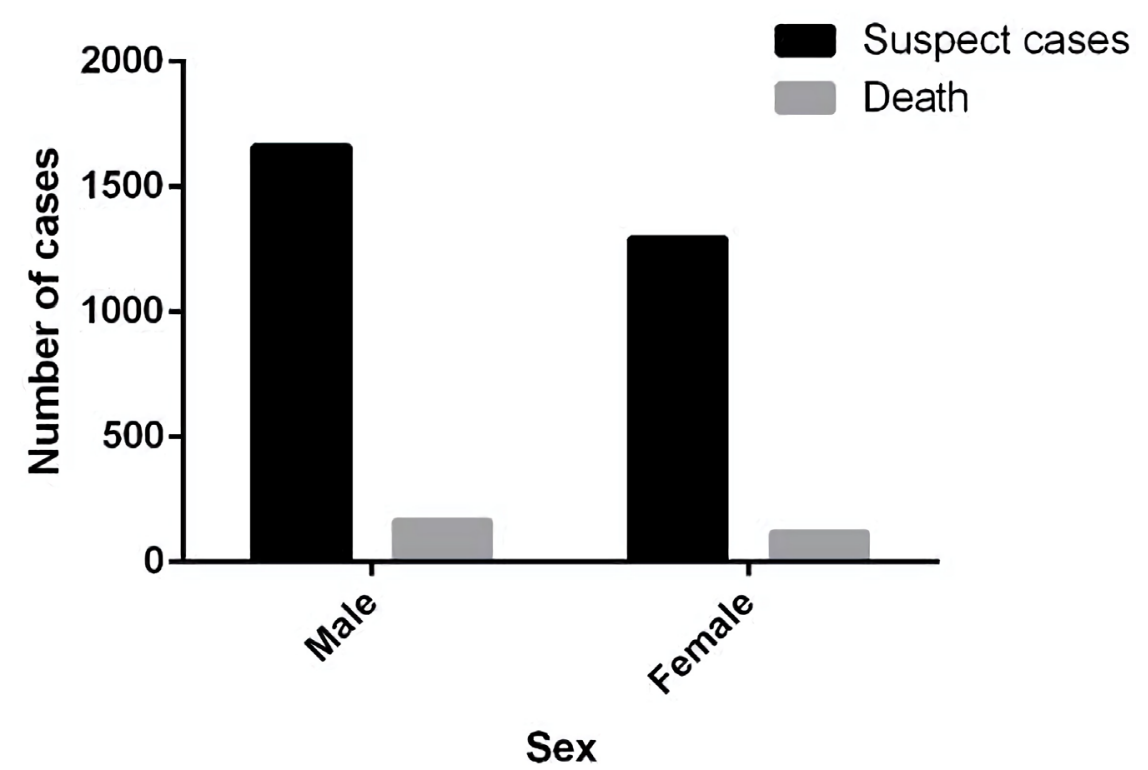

Figure 2. Sex distribution of suspected meningitis cases and deaths due to bacterial meningitis in the Republic of Benin, 2016-2018.

the year (Figure 3). It has been noted a suspicious case increase from January to April. 


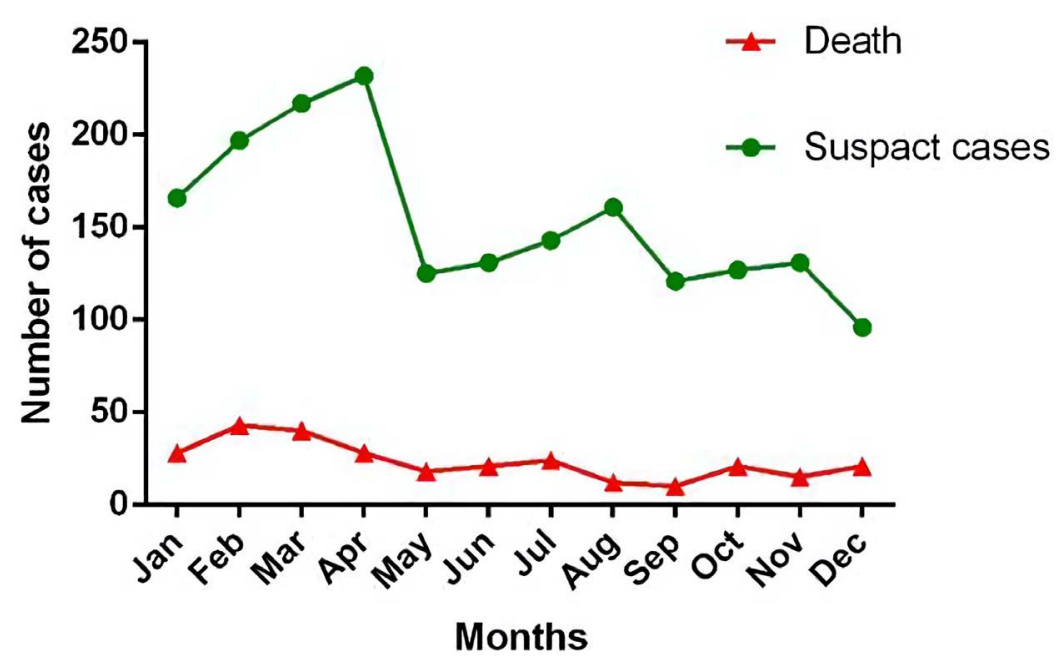

Figure 3. Number of suspected cases of bacterial meningitis and deaths by month of the year in the Republic of Benin from 2016 to 2018.

\subsection{Pathogen Distribution}

Of 2928 CSF samples analyzed in this study, 899 pathogens were identified, representing a $30.7 \%$ prevalence of meningeal bacteria. The number of pathogens identified increased during the first two years of study (312 to 318 from 2016 to 2017) and decreased over the last year (2018). During the present study, we observed a dominance of $S$. pneumoniae strains in patients. We identified more pathogens in patients (male) than in patients (female). Of the 2928 CSF samples, $54.4 \%$ were clear and $29.9 \%$ had a turbid appearance. From CSF turbid samples, was identified the highest proportion of pathogen (77\%) with a dominance of $S$. pneumoniae (60.2\%) and $N$. meningitidis (27\%) (Table 3).

A high proportion of pathogens was noted in patient under 5 years of age with S. pneumoniae (192) and N. meningitidis (65) being dominant. Similarly, in subjects over the age of 50 , there is an absence of $H$. influenzae and a high proportion of $S$. pneumoniae (42) and N. meningitidis (19) (Figure 4).

\section{Discussion}

The occurrence of a meningitis epidemic in Benin is a very complex public health problem. It is a temperate climate country and belongs to the African meningitis belt. The burden of bacterial meningitis is distributed disproportionately by location, age, and almost equally by sex. While the case-fatality rates are high, the laboratory confirmation rate is low. This low confirmation rate in the laboratory shows a high sensitivity of the case-by-case surveillance system for bacterial meningitis in the pediatric departments of hospitals in the Republic of Benin, since the results of this study showed that individuals under five accounted for the largest proportion (44.8\%) of suspected cases with $46.3 \%$ of deaths, in contrast to individuals over 60 who accounted for only $2.4 \%$ of suspected cases with $2.9 \%$ of deaths. These results are somewhat similar to those obtained by several authors [1] [4]. Kaburi et al. [1] Showed after the evaluation 
Table 3. Distribution of cerebrospinal fluid characteristics and proportion of pathogens identified by sex in the Republic of Benin from 2016 to 2018, 2016-2018.

\begin{tabular}{|c|c|c|c|c|c|}
\hline \multirow{2}{*}{ Characteristics } & \multirow{2}{*}{$\begin{array}{l}\text { Number of } \\
\text { CSF } \\
\text { samples (\%) }\end{array}$} & \multirow{2}{*}{$\begin{array}{l}\text { Number of } \\
\text { pathogens } \\
\text { dentified (\%) }\end{array}$} & \multicolumn{3}{|c|}{ Number of bacterial species identified (\%) } \\
\hline & & & H. influenzae & S. pneumoniae & N. meningitidis \\
\hline \multicolumn{6}{|l|}{$\begin{array}{c}\text { Appearance } \\
\text { of CSF samples }\end{array}$} \\
\hline Clear & $1594(54.4)$ & $129(8.1)$ & $14(10.9)$ & $91(70.5)$ & $24(18.6)$ \\
\hline Turbid & 875 (29.9) & $674(77.0)$ & $86(12.8)$ & $406(60.2)$ & $182(27.0)$ \\
\hline Hemorragic & $199(6.8)$ & $38(19.1)$ & $7(18.4)$ & $30(79.0)$ & $1(2.6)$ \\
\hline Xanthochromic & $112(3.8)$ & $52(46.4)$ & $1(2.0)$ & $41(78.8)$ & $10(19.2)$ \\
\hline Unknown & $148(5.1)$ & $6(4.1)$ & $2(33.3)$ & $2(33.3)$ & $2(33.3)$ \\
\hline \multicolumn{6}{|l|}{ Sex } \\
\hline Male & $1639(56.0)$ & $531(32.4)$ & $58(10.9)$ & $342(64.4)$ & $131(24.7)$ \\
\hline Female & $1285(43.9)$ & $366(28.5)$ & $52(14.2)$ & $227(62.0)$ & $87(23.8)$ \\
\hline Unknown & $4(0.1)$ & $2(50.0)$ & - & $1(50.0)$ & $1(50.0)$ \\
\hline \multicolumn{6}{|l|}{ Years } \\
\hline 2016 & $1069(36.5)$ & $312(29.2)$ & $52(16.7)$ & $175(56.1)$ & $85(27.2)$ \\
\hline 2017 & $1127(38.5)$ & $318(28.2)$ & $35(11.0)$ & $182(57.2)$ & $101(31.8)$ \\
\hline 2018 & $732(25.0)$ & $269(36.7)$ & $23(8.6)$ & $213(79.2)$ & $33(12.3)$ \\
\hline Total CSF analyzed & $2928(100)$ & $899(30.7)$ & $110(12.2)$ & $570(63.4)$ & $219(24.4)$ \\
\hline
\end{tabular}

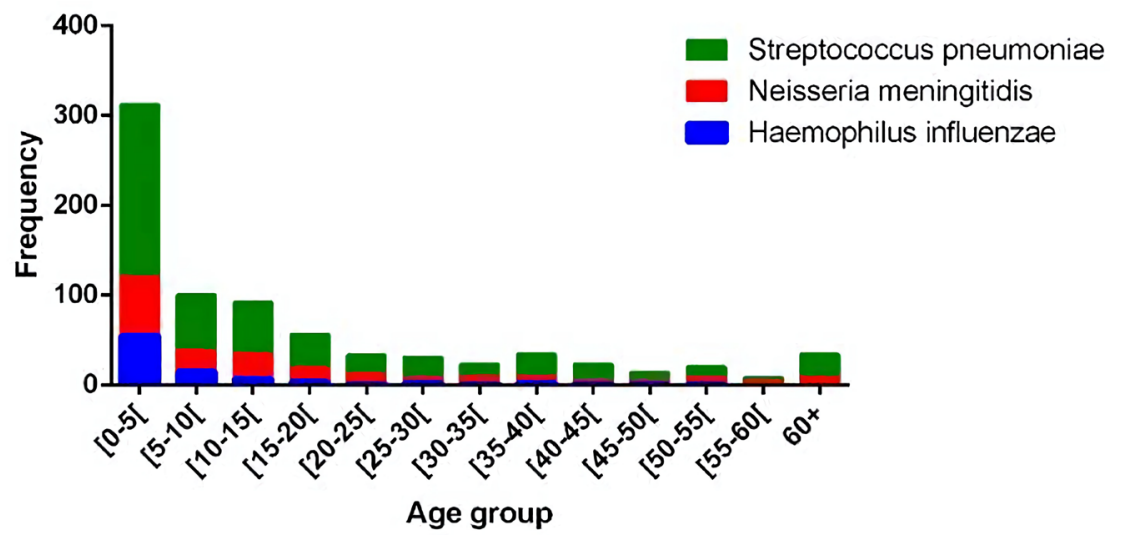

Figure 4. Distribution of meningeal bacteria according to the age group of patients in the Republic of Benin from 2016 to 2018.

of surveillance data for bacterial meningitis in northern Ghana from 2010 to 2015 , that cases of meningitis suspects were significantly higher in children under five (27.4\%) than in patients 60 years and older (4.8\%). This vulnerability of children to meningitis is attributed to their immature immune system [15]. Exposure of babies to perineal bacteria at the time of delivery would also increase the risk of bacterial meningitis early in the neonatal period [1]. Our study showed that $77.1 \%$ of suspected meningitis cases were from rural areas with 
84.3\% (237/281) deaths during the study period. This high CFR among individuals living in a rural area would be related to several factors or behaviors. At numbers of these, malnutrition, overcrowding of households, lack of vaccination, waiting to be very sick before going to hospital, home treatment and self-medication [16]. In their study of identifying the social, economic, and behavioral factors that may contribute to meningitis transmission, Hayden et al. [17] found that in rural areas of northern Ghana only 33.3\% Respondents reported vaccination as a means of protecting themselves or their family from meningitis. In addition, $42.8 \%$ of respondents said they go to the hospital when they are very sick and $18 \%$ provide home treatment by self-medication. This confirms the influence of social and behavioral factors in the occurrence of meningitis epidemics in rural areas. Our results showed a decrease in CFR of meningitis during the study period. From $13.4 \%$ in 2016, it rose to $7.6 \%$ in 2018 . This decrease CFR of meningitis has also been observed in several studies in Benin (2011 to 2016) and in the sub-region [1] [18] [19]. For example, CFR of meningitis in recent years has decreased in Benin and in most countries of the African meningitis belt (lapeyssonnie) [5], it is now comparable to that of developed countries [20]. Investments in prevention (introduction of new polysaccharide and conjugate vaccines) of bacterial meningitis over the last decade are justified by this improvement in morbidity and mortality [21]. The implementation of robust immunization programs and high-quality clinical care has contributed significantly to reducing the burden of disease in the region [22].

Benin is subdivided into 12 departments. During the present study, we recorded suspected cases of meningitis in only 10 departments. At the numbers of these, the departments of "Alibori", "Atacora" and "Borgou" represent the departments where we recorded more cases and deaths (Figure 1), with incidences/100,000 population of 13.9; 51.2 and 18.9 respectively. These three departments are found in the northern zone of Benin. This area is the part of Benin that is found in the Lapeyssonnie. This is justified by the high proportion of meningitis cases and deaths recorded in these three departments. However, we have recorded suspected cases of meningitis and deaths in other departments outside of the region. There was CFR of $12.5 \%$ in the Atlantic and Plateau departments, respectively, and $8.3 \%$ in the "Collines" department. These results show that, apart from the northern part of the country, the disease can occur in all departments from North to South and from East to West.

In this study, the majority of meningitis cases were recorded from January to April with a peak in April and 68.6\% of deaths (Figure 4). In Benin, and more precisely in the northern zone, two seasons are well defined and known. The rainy season (May to October) and the dry season with harmattan (November to April). During the dry season, the heat, the dry and dusty wind during the day, increases the risk of communicable respiratory diseases [23] [24]. Meningitis could result, if these respiratory infections are poorly managed. During the harmattan, nights are cold and people close their windows to warm up. This leads to poor ventilation. These conditions facilitate the spread of infections from one 
person to another, in an overcrowded room [17].

The prevalence of meningeal bacteria identified during this study is $30.7 \%$ with a decrease in number of pathogens over the three years of study (312 in 2016 and 218 in 2018). Our results showed a predominance of $S$. pneumoniae (63.4\%), followed by $N$. meningitidis $(24.4 \%)$ and $H$. influenzae (12.2\%). This predominance of $S$. pneumoniae on $N$. meningitidis and $H$. influenzae was also reported by several authors [1] [18] [19] [20]. The decrease in the proportion of $N$. meningitidis may be due to the introduction of MenAfriVac through mass vaccination campaigns of 1 to 29 years in 2010, but also to the improvement of the surveillance system [21]. Similarly, in 2011, Benin introduced the influenza B conjugate vaccine, which also justifies the drastic decline in $H$. influenzae involved in meningitis [21]. The proportion of $S$. pneumoniae identified in children under five in our study was $21.4 \%$ in 2016 compared to $32.4 \%$ [18]. This predominance of $S$. pneumoniae involved in cases of pneumococcal meningitis in children under five is still relevant in 2019 [18] despite the introduction of conjugate pneumococcal vaccine (PCV) in the Expanded Program on Immunization in the Republic of Benin since 2011 [21]. As a limitation, during our study, we did not record the information that registered patients were on antibiotics or not. Moreover, we have not tested the susceptibility of meningeal bacteria to antibiotics. This information could allow us to evaluate the impact of self-medication on treatment failures in terms of the management of probable cases.

\section{Conclusion}

The present study showed that the highest proportion of meningitis cases reported was in the dry season, in patients under 5 years old and predominant in boys. The burden of disease is disproportionate in the northern departments as in the rest of the country. However, deaths have been recorded in the departments of the South (Atlantic, Plateau). This suggests an improvement in epidemiological surveillance and case management throughout the national territory. This study showed the success of the PsA-TT vaccine against $N$. meningitidis A in the Republic of Benin. Overall, pneumococcus remained an important cause of infantile meningitis in the Republic of Benin, despite a gradual decline in prevalence after the PCV era. This suggests the need for closer monitoring to determine any change in disease progression soon after a decade after the introduction of PCV.

\section{Acknowledgements}

The authors thank all the staff of the epidemiological surveillance service of the Ministry of Health of Benin and all the health personnel who participated in this surveillance.

\section{Consent for Publication}

Not applicable. 


\section{Availability of Data and Materials}

The datasets supporting the conclusions of this article are included within the article.

\section{Funding}

No financial support was received for this study.

\section{Author's Contributions}

TPG, MNP, AJA, HB wrote the protocol. TPG and AJA Field work, protocol implementation, data analysis, interpretation and wrote the draft of the manuscript. TVD, CD and AA made substantial contributions to conception and study design, data analysis and interpretation.MNP, LB-M, HB participated in the critical revision of the manuscript.

\section{Conflicts of Interest}

The authors declare that they have no competing interests.

\section{References}

[1] Kaburi, B.B., Kubio, C., Kenu, E., Ameme, D.K., Mahama, J.Y., Sackey, S.O. and Afari, E.A. (2017) Evaluation of Bacterial Meningitis Surveillance Data of the Northern Region, Ghana, 2010-2015. Pan African Medical Journal, 27, 164. https://doi.org/10.11604/pamj.2017.27.164.11036

[2] World Health Organization (2017) Meningococcal Meningitis. Fact Sheet. World Health Organization, Geneva. http://www.who.int/mediacentre/factsheets/fs141/en

[3] La Force, F.M. and Okwo-Bele, J.M. (2011) Eliminating Epidemic Group A Meningococcal Meningitis in Africa through a New Vaccine. Health Affairs, 30, 1049-1057. https://doi.org/10.1377/hlthaff.2011.0328

[4] Nuoh, R.D., Nyarko, K.M., Nortey, P., Sackey, S.O., Lwanga, N.C., Ameme, D.K., Nuolabong, C., Abdulai, M., Wurapa, F. and Afari, E. (2016) Review of Meningitis Surveillance Data, Upper West Region, Ghana 2009-2013. Pan African Medical Journal, 25, 9. https://doi.org/10.11604/pamj.supp.2016.25.1.6180

[5] Lapeyssonnie, L. (1963) Cerebrospinal Meningitis in Africa. Bulletin World Health Organization, 28, 1-114.

https://www.ncbi.nlm.nih.gov/pmc/articles/PMC2554630/pdf/bullwho00305-0005.p df

[6] World Health Organization (2012) Emergencies Preparedness, Response. Meningococcal Disease: Situation in the African Meningitis Belt. http://www.who.int/csr/don/2012 05 24/en

[7] Munguambe, A.M., de Almeida, A.E.C., Nhantumbo, A.A., Come, C.E., Zimba, F.T., Langa, J.P., de Filippis, I. and Gudo, E.S. (2018) Characterization of Strains of Neisseria meningitidis Causing Meningococcal Meningitis in Mozambique, 2014: Implications for Vaccination against Meningococcal Meningitis. PLoS ONE, 13, e0197390. https://doi.org/10.1371/journal.pone.0197390

[8] Lingani, C., Bergeron-Caron, C., Stuart, J.M., et al. (2015) Meningococcal Meningitis Surveillance in the African Meningitis Belt, 2004-2013. Clinical Infectious Dis- 
eases, 61, S410-S415. https://doi.org/10.1093/cid/civ597

[9] Collard, J.-M., Issaka, B., Zaneidou, M., Hugonnet, S., Nicolas, P., Taha, M.-K., Greenwood, B. and Jusot, J.-F. (2013) Epidemiological Changes in Meningococcal Meningitis in Niger from 2008 to 2011 and the Impact of Vaccination. BMC Infectious Diseases, 13, Article No. 576. http://www.biomedcentral.com/1471-2334/13/576

[10] Djohy, G., Edja, A.H. and Djohy, M.S. (2015) Représentations Populaires De La Méningite Épidémique Dans Un Contexte De Changement Climatique $\mathrm{Au}$ Nord-Bénin. Sciences Sociales et Santé, 33, 47-74. https://doi.org/10.3917/sss.331.0047

[11] Manzo, L.M., Ousmane, S., Ibrahim, D.D., Zaneidou, M., Testa, J. and Maïnassara, H.B. (2018) Bacterial Meningitis in Niger: An Analysis of National Surveillance Data, 2003-2015. Pan African Medical Journal, 30, 235. https://doi.org/10.11604/pamj.2018.30.235.15937

[12] MEPN (Ministère de l'Environnement et de la Protection de la Nature) (2008) Programme d'action nationald'adaptation aux changements climatiques du Bénin. Convention-cadre des Nations Unies sur les Changements Climatiques, Cotonou, Bénin, 81 p. https://unfccc.int/resource/docs/napa/ben01f.pdf

[13] INSAE (Institut National de la Statistique et de l'Analyse Economique) (2013) Résultats provisoires RGPH4, Cotonou, Bénin: INSAE-Bénin.

[14] Houehanou-Sonou, Y.C. (2015) Epidemiology of Cardiovascular Risk Factors in Tropical Population-Case of Benin. PhD Thesis, Universities of Limoges cotutelleAbomey-Calavi.

[15] El Bashir, H., Laundy, M. and Booy, R. (2003) Diagnosis and Treatment of Bacterial Meningitis. Archives of Disease in Childhood, 88, 615-620. https://doi.org/10.1136/adc.88.7.615

[16] Daugla, D., Gami, J., Gamougam, K., et al. (2014) Effect of a Serogroup Ameningococcal Conjugate Vaccine (PsA-TT) on Serogroup Ameningococcal Meningitis and Carriage in Chad: A Community Trial. The Lancet, 383, 40047. https://doi.org/10.1016/S0140-6736(13)61612-8

[17] Hayden, M.H., Dalaba, M., Awine, T., Akweongo, P., Nyaaba, G., Anaseba, D., Pelzman, J., Hodgson, A. and Pandya, R. (2013) Knowledge, Attitudes, and Practices Related to Meningitis in Northern Ghana. American Journal of Tropical Medicine and Hygiene, 89, 265-270. https://doi.org/10.4269/ajtmh.12-0515

[18] Agossou, J., Ebruke, C., Noudamadjo, A., Adédémy, J.D., Dènon, E.Y., Bankolé, H.S., Dogo, M.A., Assogba, R., Alassane, M., et al. (2019) Declines in Pediatric Bacterial Meningitis in the Republic of Benin Following Introduction of Pneumococcal Conjugate Vaccine: Epidemiological and Etiological Findings, 2011-2016. Clinical Infectious Diseases, 69, S140-S147. https://doi.org/10.1093/cid/ciz478

[19] Hama, M.K., Khan, D., Laouali, B., Okoi, C., Yam, A., Haladou, M., Worwui, A., Ndow, P.S., et al. (2019) Pediatric Bacterial Meningitis Surveillance in Niger: Increased Importance of Neisseria meningitidis Serogroup C, and a Decrease in Streptococcus pneumoniae Following 13-Valent Pneumococcal Conjugate Vaccine Introduction. Clinical Infectious Diseases, 69, S133-S139. https://doi.org/10.1093/cid/ciz598

[20] Kwambana-Adams, B.A., Asiedu-Bekoe, F., Sarkodie, B., Afreh, O.K., Kuma, G.K., Owusu-Okyere, G., Foster-Nyarko, E., Ohene, S.-A., et al. (2016) An Outbreak of Pneumococcal Meningitis among Older Children ( $\geq 5$ Years) and Adults after the Implementation of an Infant Vaccination Programme with the 13-Valent Pneumo- 
coccal Conjugate Vaccine in Ghana. BMC Infectious Diseases, 16, 575.

https://doi.org/10.1186/s12879-016-1914-3

[21] Trotter, C.L., Lingani, C., Fernandez, K., Cooper, L.V., Bita, A., Tevi-Benissan, C., Ronveaux, O., Préziosi, M.-P. and Stuart, J.M. (2017) Impact of MenAfriVac in Nine Countries of the African Meningitis Belt, 2010-15: An Analysis of Surveillance Data. Lancet Infectious Diseases, 17, 867-872. https://doi.org/10.1016/S1473-3099(17)30301-8

[22] Mohammed, I., Iliyasu, G. and Habib, A.G. (2017) Emergence and Control of Epidemic Meningococcal Meningitis in Sub-Saharan Africa. Pathogens and Global Health, 111, 1-6. https://doi.org/10.1080/20477724.2016.1274068

[23] Codjoe, S.N. and Nabie, V.A. (2014) Climate Change and Cerebrospinal Meningitis in the Ghanaian Meningitis Belt. International Journal of Environmental Research and Public Health, 11, 6923-6939. https://doi.org/10.3390/ijerph110706923

[24] Palmgren, H. (2009) Meningococcal Disease and Climate. Global Health Action, 2, 10. https://doi.org/10.3402/gha.v2i0.2061 